\title{
Coulisses
}

Revue de théâtre

15 | Hiver 1997

Varia

\section{L'Annonce faite à Marie : Un grand moment de théâtre}

Jacques Houriez

\section{(2) OpenEdition}

Journals

Édition électronique

URL : http://journals.openedition.org/coulisses/5081

DOI : $10.4000 /$ coulisses.5081

ISSN : 2546-9460

Éditeur

Presses universitaires de Franche-Comté

\section{Édition imprimée}

Date de publication : 1 janvier 1997

Pagination : 43-44

ISSN : 1150-594X

\section{Référence électronique}

Jacques Houriez, «L'Annonce faite à Marie : Un grand moment de théâtre », Coulisses [En ligne], 15 |

Hiver 1997, mis en ligne le 26 avril 2019, consulté le 31 octobre 2019. URL : http://

journals.openedition.org/coulisses/5081 ; DOI : 10.4000/coulisses.5081

Ce document a été généré automatiquement le 31 octobre 2019.

Coulisses 


\title{
L'Annonce faite à Marie: Un grand moment de théâtre
}

\author{
Jacques Houriez
}

\section{Un lieu inadapté}

1 Le metteur en scène, Pierre Louis, et sa troupe ont présenté un spectacle de grande qualité artistique et émotionnelle. Ce ne fut pas sans mérite, et il est regrettable qu'aucun théâtre bisontin n'ait accueilli la pièce. La cathédrale paraît mal adaptée aux représentations théâtrales. Trop haute de plafond, elle n'est un lieu ni fermé ni ouvert, et l'acoustique s'y est révélée médiocre, ce qui a surtout gêné les rôles où le ton de voix se devait d'être discret.

La mise en scène a su néanmoins tirer le meilleur parti du contexte architectural qui a fourni à l'horizontalité du décor scénique un contrepoint vertical nécessaire à une pièce ancrée dans le spirituel autant que dans le charnel. L'éclairage mettait en valeur les colonnes gothiques et la chaire où une «nonne » chantait l'angélus du Prologue. L'apparition de l'ange baroque portant la croix, en altitude soulignait avec bonheur les moments forts de la spiritualité.

Dans cette mise en scène qui, faute peut-être de moyens matériels, avait fait le pari du dépouillement, l'éclairage, de Michel Boillet, notamment celui qui suggérait la forêt, palliant la pauvreté du décor, a joué un rôle déterminant pour souligner les intentions du metteur en scène.

\section{Une mise en scène dépouillée}

Cette discrétion du décor a mis en valeur les rares objets représentés, notamment le cierge pascal et la table qui devient au quatrième acte l'autel sur lequel le Père dépose Violaine, Lorraine Prigent, l'hostie sacrifiée. Le dépouillement a aussi dégagé toute la violence et la poésie d'un texte très bien servi par une distribution remarquable.

Violaine a incarné l'innocence de la jeune fille avec un rien d'ambiguïté dans le baiser 
au lépreux qui peut être aussi l'homme qu'on préfère à un fiancé trop fruste. Face à elle, et dans le quasi vide qui les entourait, Mathieu Loiseau a traduit avec perfection le désespoir, voire la rage de la passion déçue d'un Pierre de Craon pathétique et crédible. Christian Pageault et Claudine Berthet, le Père et la Mère avaient approfondi, depuis les représentations du Fort de Joux, l'été 95, des rôles difficiles où déjà ils excellaient. Miguel Fernandez incarnait parfaitement toute la pusillanimité et la détresse de Jacques Hury et Béatrice Bompas faisait admirablement ressortir l'ironie d'une Mara en révolte contre sa famille et toute autorité qui n'est pas la sienne.

Le dépouillement, en écartant le réalisme, a paradoxalement mieux révélé le caractère charnel des personnages. Il a mieux dégagé aussi leur personnalité. On l'a particulièrement ressenti dans la scène de la "fiancée à travers les branches en fleurs " où, en une absence totale de décor, Violaine et Jacques, côte à côte, puis engagés dans des poursuites mutuelles ont admirablement porté la beauté tragique du texte. Le symbolisme discret de la mise en scène, une certaine solennité dans le geste quasi sacramentel du partage du pain, le changement de décor opéré par la religieuse qui a chanté un cantique en chaire et en chante un autre, suggèrent la spiritualité. On peut certes regretter que l'affrontement entre Mara et Violaine dans la scène du miracle, si fortement ressenti par les spectateurs des journées de Joux, ait été affaibli par un dialogue qui fut plus une discussion qu'un échange violent de répliques et surtout par le retrait de Violaine lors d'une résurrection qui se fait hors de la présence du spectateur. Mais l'ensemble du spectacle a parfaitement rendu la violence souvent extrême des sentiments.

\section{Une interprétation hésitante}

4 Pierre Louis est demeuré fidèle à l'esprit de création de 1912 par Lugné-Poe. Certes, les procédés de l'époque symboliste, mélopée, psalmodie, stylisation des gestes, hiératisme des attitudes, obscurité presque totale sont aujourd'hui obsolètes, mais on a le même refus du réalisme. On a la même réduction du décor où les colonnes gothiques de la cathédrale correspondent au grand arbre dans une ouverture ogivale, le même jeu de distanciation et le même pari en faveur d'un texte jugé si riche qu'on donne à sa diction le rôle essentiel.

Les interprétations ont hésité entre celle de Philippe Adrien, de 1990, quelque peu sadienne, où tout est noir, où le mal règne et celles qui représentent le triomphe de la pureté et du sacrifice sur les forces de mort et de destruction. La première peut avoir pour justification l'atmosphère dure où baignait, au moment des premières versions, Claudel dont le christianisme très sincère consistait plus en un effort énorme pour se libérer des miasmes de sa jeunesse qu'en une pratique des vertus évangéliques. On ne saurait reprocher à Pierre Louis de s'être voulu plus proche de l'autre manière, que le texte, pratiquement, impose. Simplement, sans vouloir en faire un moderne Sida, comme Philippe Adrien, on eût préféré la lèpre plus cruelle, à l'égard, notamment, du visage de Violaine, resté trop beau, trop proche de celui de la vierge de Combernon que ne dévorait pas encore le péché des autres.

\section{Un grand moment de théâtre}

6 Quoi qu'il en soit, les comédiens des Nuits de Joux et leur metteur en scène ont offert à Besançon un grand moment de théâtre. Et l'on sait combien il est difficile et méritoire 
d'interpréter Claudel, pour une troupe surtout qui compte, comme celle-ci, un grand nombre de non professionnels. Tous ont fait l'admiration du public.

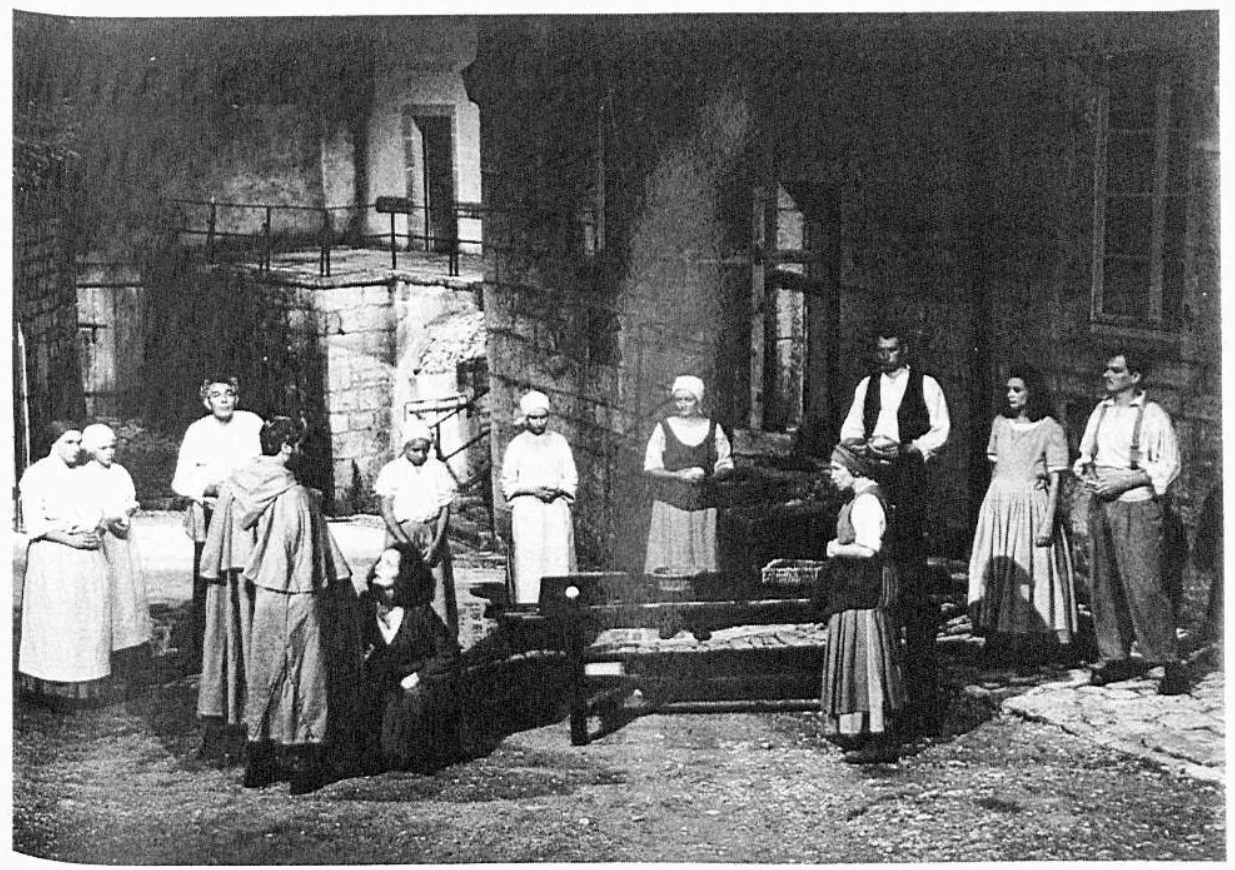

Photo Jean Daubas 